\title{
CARACTERIZAÇÃO QUÍMICA DA CARNE DE CABRITO DA RAÇA MOXOTÓ E DE CRUZAS PARDO ALPINA X MOXOTÓ 1
}

\author{
FREDERICO JOSÉ BESERRA², ANTONIA LUCIVÂNIADE SOUSAMONTE ${ }^{3}$, \\ LUCIANA CRISTINA NOGUEIRADE MORAES BEZERRA4 ${ }^{4}$ E RENATA TIEKO NASSU ${ }^{5}$
}

\begin{abstract}
RESUMO - O objetivo da pesquisa foi avaliar a composição química da carne de cabrito-mamão (idade média de 72 dias), da raça Moxotó (MOX), grupos genéticos 3/4 Pardo Alpina x 1/4 Moxotó (3/4 PAMOX) e $1 / 2$ Pardo Alpina X 1/2 Moxotó (1/2 PAMOX). A análise apresentou valores médios entre $77,80 \%$ a $80,25 \%$ de umidade; $15,90 \%$ a $19,08 \%$ de proteína; $1,12 \%$ a $1,21 \%$ de gordura, e $1,29 \%$ a $2,03 \%$ de cinzas. Quanto à composição mineral, os valores médios variaram de $5,62 \mathrm{mg} / 100 \mathrm{~g}$ a $8,21 \mathrm{mg} / 100 \mathrm{~g}$ de cálcio; $156,97 \mathrm{mg} / 100 \mathrm{~g}$ a $196,25 \mathrm{mg} / 100 \mathrm{~g}$ de fósforo; $0,26 \mathrm{mg} / 100 \mathrm{~g}$ a $0,48 \mathrm{mg} / 100 \mathrm{~g}$ de ferro; $16,25 \mathrm{mg} / 100 \mathrm{~g}$ a $23,72 \mathrm{mg} / 100 \mathrm{~g}$ de magnésio; $59,20 \mathrm{mg} / 100 \mathrm{~g}$ a $78,79 \mathrm{mg} / 100 \mathrm{~g}$ de sódio, e de $259,69 \mathrm{mg} / 100 \mathrm{~g}$ a 292,24 mg/100 g de potássio. Foram encontradas diferenças significativas a $5 \%$ de probabilidade entre os grupos genéticos no que diz respeito à composição de umidade, proteína e cinzas e mineral quanto a elementos estudados. Não houve diferenças entre os valores de gordura dos grupos genéticos.
\end{abstract}

Termos para indexação: caprinos, composição química, composição mineral.

\section{CHEMICAL CHARACTERIZATION OF KID MEAT FROM MOXOTÓ GOAT AND PARDO ALPINA X MOXOTÓ CROSSBREEDS}

\begin{abstract}
The objective of this study was to evaluate chemical composition of kid meat of Moxotó (MOX), 3/4 Pardo Alpina x 1/4 Moxotó (3/4 PAMOX) and 1/2 Moxotó x 1/2 Pardo Alpina (1/2 PAMOX) crossbreed goats. Average age of kids at slaughter was 72 days. Kids were fed with cow milk and a protein supplement. Meat analysis showed average values ranging from $77.80 \%$ to $80.25 \%$ for moisture; from $15.90 \%$ to $19.08 \%$ for protein; from $1.12 \%$ to $1.21 \%$ for fat and from $1.29 \%$ to $2.03 \%$ for ash. For mineral composition, average values ranged from $5.62 \mathrm{mg} / 100 \mathrm{~g}$ to $8.21 \mathrm{mg} / 100 \mathrm{~g}$ for calcium; from $156.97 \mathrm{mg} / 100 \mathrm{~g}$ to $196.25 \mathrm{mg} / 100 \mathrm{~g}$ for phosphorus; from $0.26 \mathrm{mg} / 100 \mathrm{~g}$ to $0.48 \mathrm{mg} / 100 \mathrm{~g}$ for iron; from $16.25 \mathrm{mg} / 100 \mathrm{~g}$ to $23.72 \mathrm{mg} / 100 \mathrm{~g}$ for magnesium; from $59.20 \mathrm{mg} / 100 \mathrm{~g}$ to $78.79 \mathrm{mg} / 100 \mathrm{~g}$ for sodium and from $259.69 \mathrm{mg} / 100 \mathrm{~g}$ to $292.24 \mathrm{mg} / 100 \mathrm{~g}$ for potassium. Genetic groups showed significative differences for composition of moisture, protein and ash values and for mineral composition, in all measured elements. Fat content values did not show statistical differences between goat genetic groups.
\end{abstract}

Index terms: chemical composition, mineral composition, goats.

\footnotetext{
${ }^{1}$ Aceito para publicação em 9 de abril de 1999.

${ }^{2}$ Eng. Químico, Dr., Dep. de Tecnologia de Alimentos (DTA), Universidade Federal do Ceará (UFC), Campus do Pici, Av. Mister Hull, 2977, Alagadiço, Caixa Postal 12.168, CEP 60356-000 Fortaleza, CE. E-mail: frejobe@hotmail.com

${ }^{3}$ Eng. Alimentos, M.Sc., DTA/UFC.

${ }^{4}$ Eng. Alimentos, DTA/UFC.

${ }^{5}$ Eng. Alimentos, M.Sc., Embrapa-Centro Nacional de Pesquisa de Agroindústria Tropical (CNPAT), Rua Dra. Sara Mesquita, 2270, CEP 60511-110 Fortaleza, CE. E-mail: renata@cnpat.embrapa.br
}

\section{INTRODUÇÃO}

O mercado de carne ovina e caprina nos países em desenvolvimento é caracterizado pelo uso intensivo do fator trabalho e de pouco capital, representado por edificações e equipamentos simples, com muitos animais sendo abatidos nas unidades criadoras, e o produto, destinado ao estabelecimento do mercado local (Oliveira \& Santos, 1994). No Nordeste brasileiro, a comercialização dos animais 
vivos é efetuada diretamente entre criadores ou por meio de comerciantes e intermediários diversos, que levam os animais para negociar nos pequenos centros urbanos, e também por marchantes que abatem os animais explorados (Oliveira \& Santos, 1994); é expressivo o volume de carne destinado ao consumo local, enquanto tem menor significado a quantidade de animais destinados ao consumo da população das capitais e principais cidades $(\mathrm{Ca}-$ valcante \& Silva, 1988).

De maneira geral, a produtividade de caprinos, assim como a dos ovinos deslanados, tem sido baixa, como resultado da inadequação alimentar ao longo do ano, da deficiência nas condições de manejo e higiene, das inadequadas épocas e idade de reprodução, e da incidência de doenças parasitárias e infecciosas. Além desses fatores, a produção é afetada pela má qualidade do produto, pela falta de canais adequados de comercialização, pela ausência de crédito e pela assistência técnica deficiente (Sousa Neto, 1987).

O consumo da carne caprina, provavelmente limitado pela oferta, constitui-se em um mercado pouco explorado. Para sua expansão, faz-se necessário uma melhor apresentação do produto nacional, padronização dos cortes, e campanhas publicitárias. O mercado internacional também apresenta amplas possibilidades de colocação do produto nacional, desde que sejam atendidos alguns requisitos de qualidade (Oliveira \& Santos, 1994).

Pouco tem sido publicado sobre a natureza da carne de caprinos do Nordeste, exceção feita aos trabalhos de Almeida (1990), Timbó (1995) e Zapata et al. (1995). É de grande importância o fornecimento de dados de composição química quantitativa das tabelas de composição de alimentos no Brasil.

Este trabalho teve como objetivo caracterizar a composição química da carne de cabrito-mamão da raça Moxotó e dos grupos genéticos $3 / 4$ Pardo Alpina $x 1 / 4$ Moxotó e $1 / 2$ Pardo Alpina x $1 / 2$ Moxotó.

\section{MATERIAL E MÉTODOS}

Usou-se neste trabalho o tecido muscular obtido da desossa da carcaça integral, separados os tecidos adiposo e conectivo, de um lote de 24 cabritos-mamão, com idade média de 72 dias, da raça Moxotó puro (MOX) e grupos genéticos 3/4 Pardo Alpina x 1/4 Moxotó (3/4 PAMOX) e $1 / 2$ Pardo Alpina X $1 / 2$ Moxotó (1/2 PAMOX). Oito animais, de cada grupo genético, foram arraçoados durante os meses de março a maio de 1995, em instalações da EmbrapaCentro Nacional de Pesquisas de Caprinos, situado em Sobral, Ceará. O programa de alimentação empregado constou de aleitamento artificial com leite bovino, por meio de mamadeira coletiva, por um período de 64 dias, e suplementação na última semana à base de concentrado protéico constituído de milho e soja, na proporção de 70:30.

Os animais foram submetidos a jejum alimentar e hídrico de 24 horas e o abate foi realizado segundo método tradicional; insensibilização mediante concussão cerebral com uso de marreta, sangria, esfola e evisceração. As carcaças foram acondicionadas em sacos de polietileno (PE) e resfriadas a $0^{\circ} \mathrm{C}$, por um período de 12 horas. A seguir, foram armazenadas em câmara frigorífica, à temperatura de $-10^{\circ} \mathrm{C}$, por um período de três a sete dias. As carcaças foram descongeladas à temperatura média de $5 \pm 2{ }^{\circ} \mathrm{C}$, no Laboratório de Carnes do Departamento de Tecnologia de Alimentos da Universidade Federal do Ceará. Após a desossa, realizada manualmente, o tecido muscular foi triturado em moinho de carne (placas com $6 \mathrm{~mm}$ de diâmetro), homogeneizado finamente em multiprocessador, acondicionado em sacos de polietileno, congelado, e armazenado em câmara frigorífica a $-10^{\circ} \mathrm{C}$, para posterior utilização.

Para as análises da composição química e mineral, empregaram-se amostras em triplicatas do tecido muscular homogeneizado, utilizando as metodologias descritas a seguir:

a) Umidade, gordura e cinzas (resíduo mineral fixo), de acordo com metodologia da Association of Analytical Chemists (1984);

b) Proteína, pelo método de micro Kjeldahl, de acordo com a American Association of Cereal Chemists (1969);

c) Cálcio: por espectrofotometria, de acordo com o método de Harris (1991);

d) Fósforo: por espectrofotometria, de acordo com a Association of Analytical Chemists (1984);

e) Ferro: por espectrofotometria, segundo Christian (1986); f) Magnésio: por espectrofotometria de absorção atômica, segundo Harris (1991);

g) Sódio e potássio: por fotometria de chama, segundo Harris (1991).

Quanto à análise estatística, para o estudo de efeito da raça sobre cada variável, foram usadas a técnica paramétrica de análise de variância e comparações de médias pelo teste de Tukey, através do programa estatístico SPSS (SPSS Inc., 1995). As variáveis expressas em porcentagem foram transformadas para arc sen $(\mathrm{v} / 100)^{1 / 2}$. Nos resultados, foi considerada a significância de 5\%. 


\section{RESULTADOS E DISCUSSÃO}

Os valores médios de umidade, proteína, gordura e cinza obtidos do tecido muscular dos animais pertencentes aos grupos genéticos estudados, estão indicados na Tabela 1. Os grupos apresentaram diferenças $(\mathrm{P}<0,05)$ nos componentes umidade, proteína e minerais.

Com relação aos teores de umidade, a análise dos dados mostrou pequenas variações dentro de cada grupo genético, registrando-se os menores teores $(77,49$ a $77,93 \%)$ em $1 / 2$ PAMOX e os maiores teores $(79,35$ a $80,54 \%)$ em MOX. Os resultados obtidos na cruza 3/4 PAMOX foram semelhantes aos reportados por Timbó (1995), que obteve, para o híbrido 3/4 Pardo Alpina x 1/4 Moxotó com três meses de idade, 78,47\% de umidade. Quanto à cruza 1/2 PAMOX, os dados encontrados neste trabalho foram inferiores aos citados por Timbó (1995), que relata valores de $80,82 \%$ para animais da mesma raça e idade. Resultados de umidade similares também foram reportados por Park et al. (1991), que encontraram nos músculos Longissimus dorsi e Biceps femoris de caprinos pós-desmamados da raça Alpina do Texas, 79,2 e $80,40 \%$ respectivamente. Zapata et al. (1995), estudando o efeito da adição de Fe injetável como suplemento à dieta de cabrito-mamão com 72 dias de idade, do grupo genético $1 / 2$ Moxotó x 1/2 Pardo Alpina, obtiveram, no tecido muscular integral, valores de umidade inferiores em 5,0\% aos encontrados neste estudo. Almeida (1990), ao analisar músculos derivados de cortes de caprinos SRD (Sem Raça Definida), obteve, na paleta, $69,15 \%$, e $72,70 \%$ de umidade no pernil. Babiker et al. (1990) obtiveram
$75,04 \%$ de umidade em músculos Semimembranosus de caprinos do deserto do Sudão alimentados com concentrado à base de sorgo, algodão, trigo e amendoim, teores esses inferiores aos deste trabalho.

No que se refere à variação de proteína, observou-se menor variabilidade em 3/4 PAMOX $(17,01$ a $17,77 \%)$, e maior em $\operatorname{MOX}(15,29$ a $16,38 \%)$. Os menores teores de proteína foram encontrados em MOX e os maiores em 1/2 PAMOX. Quando comparados aos citados por Timbó (1995), tais resultados apresentam-se superiores no grupo genético 1/2 PAMOX e idênticos no grupo genético 3/4 PAMOX. Valores de proteína superiores, em MOX e 3/4 PAMOX, e similares, em 1/2 PAMOX, foram constatados por Almeida (1990), na paleta $(19,75 \%)$ e no pernil $(18,75 \%)$ de caprinos SRD. Babiker et al. (1990) citam, no músculo Semimembranosus de cabras do deserto do Sudão, conteúdos de proteína superiores em $23,50 \%$ aos valores obtidos em MOX, 16,53\% em 3/4 PAMOX, e $8,23 \%$ em 1/2 PAMOX. Gonzalez et al. (1983) citam em caprinos Criollos do norte do México, teores de proteína em torno de $19,84 \%$ a $23,98 \%$. Foram citados registros de $19,25 \%$ de proteína (Dantilo \& Gongiu, 1974) e de 18,99\% (Zapata et al., 1995), semelhantes ao obtido neste trabalho em $1 / 2$ PAMOX.

A análise do teor de gordura evidenciou intervalos de valores entre $0,91 \%$ a $1,40 \%$ em MOX, $0,94 \%$ a $1,50 \%$ em $3 / 4$ PAMOX, e $1,01 \%$ a $1,50 \%$ em 1/2 PAMOX. Almeida (1990) obteve no pernil e na paleta de caprinos SRD, valores de teor de gordura, variando de 7,8\% a $12,30 \%$. Gonzalez et al. (1983) encontraram 7,9\% a $16,12 \%$ em carne de caprinos Criollos do norte do México. Em raças típi-

TABELA 1. Valores médios e desvios-padrão de componentes da carne de cabrito-mamão dos grupos genéticos estudados ${ }^{1}$.

\begin{tabular}{|c|c|c|c|c|}
\hline Grupo genético $^{2}$ & Umidade & Proteína & Gordura & Cinzas \\
\hline & \multicolumn{4}{|c|}{ - } \\
\hline MOX & $80,25 \pm 0,39 a$ & $15,90 \pm 0,35 \mathrm{a}$ & $1,12 \pm 0,20 \mathrm{a}$ & $1,55 \pm 0,03 \mathrm{a}$ \\
\hline 3/4 PAMOX & $78,48 \pm 0,17 b$ & $17,36 \pm 0,23 b$ & $1,21 \pm 0,19 \mathrm{a}$ & $1,29 \pm 0,10 b$ \\
\hline 1/2 PAMOX & $77,80 \pm 0,13 \mathrm{c}$ & $19,08 \pm 0,29 \mathrm{c}$ & $1,13 \pm 0,16 \mathrm{a}$ & $2,03 \pm 0,03 \mathrm{c}$ \\
\hline
\end{tabular}

${ }^{1}$ Em cada coluna, médias seguidas da mesma letra não são diferentes pelo teste de Tukey a $\mathrm{P}<0,05$.

2 MOX: Moxotó; 3/4 PAMOX: 3/4 Pardo alpina x 1/4 Moxotó; 1/2 PAMOX: 1/2 Pardo Alpina x 1/2 Moxotó. 
cas do Nordeste brasileiro foram encontrados valores de gordura superiores em 6,0\% (Lucchesi et al., 1986), e inferiores em 65,0\% (Timbó, 1995), nas raças híbridas Moxotó x Pardo Alpina. Zapata et al. (1995) determinaram, em híbridos $1 / 2$ Moxotó $\mathrm{x} 1 / 2$ Pardo Alpina, um conteúdo de $3,98 \%$ de gordura, em média $72,0 \%$ superior aos dos três grupos utilizados neste experimento. Kondaiah \& Sharma (1989) mencionam porcentagens de gordura em torno de 3,5\% em músculos de caprinos indianos com um ano de idade, resultado análogo ao citado por Timbó (1995), ao mencionar Elgasin \& Alkanhal (1991), que ao analisarem caprinos provenientes da Arábia Saudita, registraram um teor médio em torno de 3,35\%. Concentrações de gordura superiores também foram reportadas por Park et al. (1991), que, ao estudarem os músculos Longissimus dorsi e Biceps femoris de caprino pós-desmame da raça Alpina do Texas, encontraram valores de $2,27 \%$ e $2,03 \%$, respectivamente. Os baixos teores de gordura encontrados neste estudo podem estar associados à baixa idade com a qual os animais foram abatidos, ou, ainda, ao pobre plano nutricional utilizado.

O conteúdo de resíduo mineral fixo se apresentou semelhante entre MOX e 1/4 PAMOX, com variações entre 1,25 e 1,59\%, o que corresponde a um intervalo inferior ao encontrado em 1/2 PAMOX, que se situou entre 2,0 e 2,09\%. O intervalo de valores de cinzas citados para MOX e 3/4 PAMOX encontramse acima dos citados por Timbó (1995) em animais aos três meses de idade do grupo genético $1 / 2$ Pardo Alpina x $1 / 2$ Moxotó e $3 / 4$ Pardo Alpina x 1/2 Moxotó; por Almeida (1990), em paleta e pernil de caprino SRD $1,02 \%, 1,01 \%, 0,85 \%$ e $0,95 \%$, respectivamente, e por Zapata et al. (1995), que relata um conteúdo médio de $1,04 \%$ em híbridos $1 / 2$ Pardo Alpina $\mathrm{x}$ $1 / 2$ Moxotó. Babiker et al. (1990), ao estudarem o músculo Semimembranosus em caprinos do deserto sudanês, encontraram valores de cinzas em torno de $1,23 \%$, que são semelhantes aos verificados para 3/4 PAMOX.

De maneira geral, os valores da composição centesimal obtidos neste trabalho se assemelham aos apresentados pelas distintas citações bibliográficas, que fazem referência a animais de diferentes raças e/ou grupos genéticos, originárias de diferentes continentes. Em relação ao trabalho desenvolvido por Timbó (1995), que estudou os grupos 3/4 PAMOX e 1/2 PAMOX sob um distinto sistema de produção e plano nutricional, obtiveram-se conteúdos superiores em relação aos teores de cinza e gordura, conteúdos semelhantes de proteína, e inferiores de umidade, em ambos os grupos.

Os dados referentes às determinações de $\mathrm{Ca}, \mathrm{P}$, $\mathrm{Fe}, \mathrm{Mg}, \mathrm{Na}$ e $\mathrm{K}$ dos três grupos genéticos pesquisados, com suas respectivas médias, encontram-se expostos na Tabela 2. Estatisticamente, os grupos estudados apresentaram comportamentos distintos, isto é, foram diferentes $(\mathrm{P}<0,05)$ quanto ao acúmulo dos diferentes elementos minerais no tecido muscular.

Os teores de Ca oscilaram entre 5,62 mg/100 g, em MOX, e 8,21 mg/100 g em 1/2 PAMOX. A maior variação foi observada em $3 / 4$ PAMOX $( \pm 0,30 \mathrm{mg} / 100 \mathrm{~g})$, e a menor, em $1 / 2$ PAMOX $( \pm 0,11 \mathrm{mg} / 100 \mathrm{~g}) ; 3 / 4$ PAMOX apresentou um teor médio de $6,80 \mathrm{mg} / 100 \mathrm{~g}$. Esses valores se aproximam dos reportados por Park (1990), obtidos no estudo

TABELA 2. Valores médios e desvios-padrão de componentes minerais da carne de cabrito-mamão dos grupos genéticos estudados ${ }^{1}$.

\begin{tabular}{|c|c|c|c|c|c|c|}
\hline $\begin{array}{l}\text { Grupo } \\
\text { genético }^{2}\end{array}$ & Cálcio & Fósforo & Ferro & Magnésio & Sódio & Potássio \\
\hline & \multicolumn{6}{|c|}{ 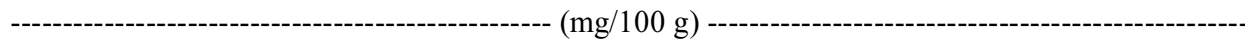 } \\
\hline MOX & $5,62 \pm 0,15 \mathrm{a}$ & $168,58 \pm 0,80 \mathrm{a}$ & $0,35 \pm 0,02 \mathrm{a}$ & $16,25 \pm 0,16 \mathrm{a}$ & $69,21 \pm 0,80 \mathrm{a}$ & $292,24 \pm 4,62 \mathrm{a}$ \\
\hline 3/4 PAMOX & $6,80 \pm 0,30 \mathrm{~b}$ & $156,97 \pm 1,11 b$ & $0,26 \pm 0,02 b$ & $19,22 \pm 0,17 \mathrm{~b}$ & $59,20 \pm 0,60 \mathrm{~b}$ & $259,69 \pm 0,80 b$ \\
\hline 1/2 PAMOX & $8,21 \pm 0,11 \mathrm{c}$ & $196,25 \pm 1,13 \mathrm{c}$ & $0,48 \pm 0,05 c$ & $23,72 \pm 0,13 \mathrm{c}$ & $78,79 \pm 1,19 \mathrm{c}$ & $285,87 \pm 0,71 \mathrm{c}$ \\
\hline
\end{tabular}

${ }^{1}$ Em cada coluna, médias seguidas da mesma letra não são diferentes pelo teste de Tukey a $\mathrm{P}<0,05$.

2 MOX: Moxotó; 3/4 PAMOX: 3/4 Pardo alpina x 1/4 Moxotó; 1/2 PAMOX: 1/2 Pardo Alpina x 1/2 Moxotó. 
da composição mineral de caprinos texanos, que fo$\mathrm{ram} 7,90 \mathrm{mg} / 100 \mathrm{~g}$ de Ca na Alpina e $8,21 \mathrm{mg} / 100 \mathrm{~g}$ na raça Nubiana. Concentrações inferiores nesse mineral foram reportados por Almeida (1990) em relação à paleta e pernil de caprinos SRD, respectivamente com $4,83 \mathrm{mg} / 100 \mathrm{~g} \mathrm{e} 4,38 \mathrm{mg} / 100 \mathrm{~g}$.

As variações médias nos conteúdos de P oscilaram entre 156,97 (3/4 PAMOX) a $196,25 \mathrm{mg} / 100 \mathrm{~g}$ (1/2 PAMOX). Esses valores equivalem aos encontrados em caprinos SRD por Almeida (1990) na paleta $(150,00 \mathrm{mg} / 100 \mathrm{~g})$ e no pernil $(180,00 \mathrm{mg} / 100 \mathrm{~g})$, em caprino da África $(155,50 \mathrm{mg} / 100 \mathrm{~g})$. Park (1990), estudando o efeito da raça, sexo e tecidos nas concentrações de macrominerais em carne de caprinos texanos, encontrou valores de $\mathrm{P}$ consideravelmente mais elevados $(232,8 \mathrm{mg} / 100 \mathrm{~g})$ na raça Alpina e na raça Nubiana $(227,3 \mathrm{mg} / 100 \mathrm{~g})$.

As oscilações médias obtidas nos teores de $\mathrm{Fe}$ nos três grupos genéticos estudados permitem detectar um intervalo de valores de $0,34 \mathrm{mg} / 100 \mathrm{~g}$ a $0,41 \mathrm{mg} / 100 \mathrm{~g}$ em MOX, 0,24 mg/100 g a $0,29 \mathrm{mg} / 100 \mathrm{~g}$ em 3/4 PAMOX, enquanto $1 / 2$ PAMOX apresentou os maiores teores, de $0,44 \mathrm{mg} / 100 \mathrm{~g} \mathrm{a} 0,59 \mathrm{mg} / 100 \mathrm{~g}$. Esses valores de $\mathrm{Fe}$ apresentam-se inferiores aos descritos por Almeida (1990), obtidos em paleta $(5,40 \mathrm{mg} / 100 \mathrm{~g})$ e no pernil $(5,98 \mathrm{mg} / 100 \mathrm{~g})$ de caprinos SRD. Zapata et al. (1995), estudando o efeito da suplementação de Fe injetável no músculo de cabrito-mamão, e nos grupos genéticos Moxotó $\mathrm{x}$ Pardo Alpina, não encontrou diferenças significativas entre os níveis de $\mathrm{Fe}$ aplicados. Como conteúdo médio, obteve $1,4 \mathrm{mg} / 100 \mathrm{~g}$, teor superior aos registrados neste trabalho, o que pode ser explicado pelo fato de a dieta empregada no seu estudo ser uma fonte eficaz desse mineral.

Os baixos teores de Fe detectados nesse estudo se justificam ao considerar-se o plano nutricional a que foram submetidos, já que o leite bovino é deficiente em Fe (Tagle, 1981; Chaves, 1985; Angelis, 1986; Sgarbieri, 1987). Também é relevante a baixa idade dos animais utilizados. De acordo com Chaves (1985), Lawrie (1985), Charley (1987) e Pardi et al. (1993), este teor é proporcional ao conteúdo de mioglobina, que por sua vez é influenciado por fatores como raça, sexo, tipo de músculo, atividade físi- ca, estado de saúde e idade. Segundo Matzke \& Bogner (1973), ao aumentar a idade, modifica-se não só a composição da carcaça, mas também a cor da carne, exibindo os animais mais jovens uma coloração mais pálida.

$\mathrm{O}$ conteúdo de $\mathrm{Mg}$ entre os grupos variou entre 16,25 (MOX) a 23,72 mg/100 g (1/2 PAMOX). Dentro dos grupos se verificou uma variação semelhante, em MOX e em 3/4 PAMOX $( \pm 0,16 \mathrm{mg} / 100 \mathrm{~g}$ a $\pm 0,17 \mathrm{mg} / 100 \mathrm{~g})$, registrando em 1/2 PAMOX a menor variação $( \pm 0,13 \mathrm{mg} / 100 \mathrm{~g})$. Essas médias se assemelham aos valores de $\mathrm{Mg}$ reportados por Almeida (1990), no pernil, 16,39 mg/100 g, e na paleta, $17,30 \mathrm{mg} / 100 \mathrm{~g}$. Park (1990) cita concentrações de $\mathrm{Mg}$ semelhantes em caprinos da raça Nubiana $(23,5 \mathrm{mg} / 100 \mathrm{~g})$ e ligeiramente superiores na raça Alpina $(24,1 \mathrm{mg} / 100 \mathrm{~g})$.

A análise dos dados referentes a teores de $\mathrm{Na}$ permite visualizar uma oscilação dos valores médios entre os grupos, de 59,20 mg/100 g para 3/4 PAMOX, 69,21 mg/100 g para MOX, e $78,79 \mathrm{mg} / 100 \mathrm{~g}$ para 1/4 PAMOX. Esse intervalo de valores de $\mathrm{Na}$ se assemelha aos reportados por Park (1990), em caprinos da raça Alpina, 69,8 mg/100 g, e Nubiana, 74,0 mg/100 g, e aos valores obtidos por Almeida (1990), em caprinos SRD, que foram 63,87 $\mathrm{mg} / 100 \mathrm{~g}$ no pernil, e, 79,49 mg/100 g na paleta.

Em relação ao $\mathrm{K}$, os dados indicam maior variabilidade de $\mathrm{K}$ nos animais do grupo MOX $( \pm 4,62 \mathrm{mg} / 100 \mathrm{~g})$ e menor nos do grupo $1 / 2$ PAMOX $( \pm 0,71 \mathrm{mg} / 100 \mathrm{~g})$. O grupo 3/4 PAMOX registrou, em média, 259,69 mg/100 g. Park (1990) obteve, em caprinos das raças Alpina e Nubiana, valores de K superiores aos verificados neste experimento. Almeida (1990), ao pesquisar a paleta de caprino SRD, verificou uma concentração de K superior em 2,0\% aos valores obtidos para 3/4 PAMOX e inferiores em 9,37\% para MOX, e em $7,35 \%$ para $1 / 2$ PAMOX. Valor próximo ao verificado para MOX foi reportado por esse mesmo autor no pernil $(293,77 \mathrm{mg} / 100 \mathrm{~g})$ de animais da mesma espécie e raça.

As diferenças observadas na composição química entre a raça Moxotó (MOX) e os grupos genéti$\cos 3 / 4$ Pardo Alpina x 1/4 Moxotó (3/4 PAMOX) e $1 / 2$ Pardo Alpina X 1/2 Moxotó (1/2 PAMOX) devem-se às peculiaridades do aparelho digestivo dos rumi- 
nantes inerentes à variabilidade genética entre os grupos estudados, no que se refere à forma diferenciada de absorção de nutrientes, fato amplamente relatado na literatura (Conrad, 1966; Church \& Pond, 1974; Caielli, 1977; Andrigueto et al., 1981).

\section{CONCLUSÕES}

1. A composição química apresenta pouca variabilidade nos grupos genéticos estudados.

2. Os três grupos genéticos estudados apresentam comportamentos distintos para acúmulo de minerais $(\mathrm{Ca}, \mathrm{P}, \mathrm{Mg}, \mathrm{Na}, \mathrm{K}$ e Fe) no tecido muscular.

3. Os valores encontrados, com exceção do teor de Fe e de gordura, se assemelham aos das citações bibliográficas referentes a animais de diferentes raças, originárias de diferentes continentes, o que é um indicativo da qualidade nutricional da carne dos cabritos-mamão dos grupos genéticos estudados.

\section{REFERÊNCIAS}

ALMEIDA, M.M.M. Estudo da composição química das carnes de caprinos e ovinos no sertão do Ceará. Fortaleza : Universidade Federal do Ceará, 1990. 78p. Dissertação de Mestrado.

AMERICAN ASSOCIATION OF CEREAL CHEMISTS. Approved methods of the American Association of Cereal Chemists. 7.ed. St Paul, 1969.

ANDRIGUETO, J.M.; PERLI, L.; MINARDI, I.; GEMAEL, A.; FLEMMING, J.S.; SOUZA, G.A.; BONA FILHO, A. Nutrição animal. São Paulo : Nobel, 1981. v.1, 395p.

ANGELIS, R.C. Fisiologia da nutrição. 3.ed. São Paulo : Nobel, 1986. v.1, 320p.

ASSOCIATION OF ANALYTICAL CHEMISTS. Official methods of analysis. Washington, 1984. $1018 \mathrm{p}$.

BABIKER, S.A.; KHIDER, J.A.E.; SHAFIE, S.A. Chemical composition and quality attributes of goat meat and lamb. Meat Science, v.28, p.273-277, 1990.

CAIELLI, E.L. Disponibilidade de nutrientes nos alimentos. In: SIMPÓSIO DE NUTRIÇÃO DE BOVINOS, 1., Piracicaba, 1977. Anais. Piracicaba : ESALQ, 1977. p.233-269.
CAVAlCANTE, G.; SILVA, R.C. Aspectos da ovinocaprinocultura do Nordeste. Recife : SUDENE, 1988. 36p.

CHARLEY, H. Tecnología de alimentos: processos químicos y físicos en la preparación de alimento. México : LIMUSA, 1987. 767p.

CHAVES, N. Nutrição - básica e aplicada. 2.ed. Rio de Janeiro : Guanabara, 1985. 370p.

CHRISTIAN, G.D. Analytical chemistry. 4.ed. New York : John Wiley \& Sons, 1986. 676p.

CHURCH, D.C.; POND, W.G. Basic animal nutrition and feeding. 3.ed. New York : John Wiley \& Sons, 1974. $472 \mathrm{p}$.

CONRAD, H.R. Physiological and physical factors limiting feed intake . Journal of Animal Science, v.25, p.227-235, 1966.

DANTILO, M.; GONGIU, F. Rafronto delle caratteristiche chimico-fisiche fra le carni di capritto e d'agnello. Atti della Società Italiana delle Scienze Veterinarie, v.27, p.437-441, 1974.

GONZALEZ, N.F.A.; OWN, J.E.; CERECERES, M.T.A. Studies on the Criollo goat of northern Mexico : Part 2 - Physical and chemical characteristics of the muscular. Meat Science, v.9, p.305-314, 1983.

HARRIS, D.C. Quantitative chemical analysis. New York : W. H. Freeman, 1991. 782p.

KONDAIAH, N.; SHARMA, N. Improving the quality of goat meat. Indian Journal of Animal Science, v.59, n.1, p.152-157, 1989.

LAWRIE, R.A. Meat science. 4.ed. Oxford : Pergamon, 1985. $267 \mathrm{p}$.

LUCCHESI, L.; SIQUEIRA, E.R. de; TAVARES, S.V. Caprinocultura. Campinas : CATI, 1986. 114p.

MATZKE, P.; BOGNER, H. Tecnología de la carne. Zaragoza : ACRIBIA, 1973. 118p.

OLIVEIRA, A.A.P.; SANTOS, V.P.M.L. Aspectos econômicos da ovino-caprinocultura tropical brasileira. In: SEMANA DA CAPRINOCULTURA E DA OVINOCULTURA TROPICAL BRASILEIRA, 1 ., 1994, Sobral. Anais. Sobral : Embrapa-SPI, 1994. p.7-45.

PARDI, M.C.; SANTOS, I.J.; SOUZA, E.R.; PARDI, H.S. Ciência, higiene e tecnologia da carne. Goiânia : EDUFF, 1993. v.1, Parte 1, 2, p.15-127. 
PARK, Y.W. Effect of breed, sex and tissues on concentration of macrominerals in goat meat. Journal of Food Science, v.55, n.2, p.308-311, 1990.

PARK, Y.W.; KOUASSI, M.A.; CHIN, K.B. Moisture, total fat and cholesterol in goat organ and muscle meat. Journal of Food Science, v.56, n.5, p.1191-1193, 1991.

SGARBIERI, V. Alimentação e nutrição - fator de saúde e desenvolvimento. São Paulo : ALMED, 1987. $387 \mathrm{p}$.

SOUSA NETO, J. de. Demanda potencial de carne de caprino e ovino e perspectivas de oferta - 1985/ 1990. Sobral : Embrapa-DDT, 1987. 16p.

SPSS INC. (Chicago, Estados Unidos). Statistical Package for the Social Sciences. Version 4. Chicago, 1995.
TAGLE, M.A. Nutrição. São Paulo : Artes, 1981. 233p.

TIMBÓ, M.O.P. Estudo do rendimento de carcaça e de algumas propriedades da carne de caprinos da raça Moxotó x Pardo Alpino. Fortaleza : Universidade Federal do Ceará, 1995. 101p. Dissertação de Mestrado.

ZAPATA, J.F.F.; BARROS, N.N.; VASCONCELOS, N.M.S. Carcass tissue distribution and composition of the lean meat from kids fed an iron supplemented diet. In: ANNUAL INTERNATIONAL CONGRESS OF MEAT SCIENCE AND TECHNOLOGY, 41., 1995, San Antonio, Texas. Proceedings. San Antonio, Texas : American Meat Science Association, 1995. p.40-42. 